\title{
Minimal Conditions to Degrade Low Density Polyethylene by Aspergillus terreus and niger
}

\author{
Melina Sáenz ${ }^{1 *}$, Tamara Borodulina ${ }^{1}$, Linda Diaz² ${ }^{2}$ Carlos Banchon ${ }^{1}$ \\ 1 Universidad Agraria del Ecuador (UAE), Environmental Engineering, Faculty of Agrarian Sciences, Av. 25 de \\ Julio and P. Jaramillo, 59304, Guayaquil, Ecuador \\ 2 Instituto Nacional de Investigación en Salud Pública (INSPI) - Dr. Leopoldo Izquieta Pérez, Julián Coronel 905, \\ Guayaquil, Ecuador \\ * Corresponding author's e-mail: melinasaenzarias@gmail.com
}

\begin{abstract}
Plastics pollution is a major worldwide concern because there is strong evidence about marine influence on the human trophic chain. Thus, we experimented with the biodegradation of low density polyethylene (LDPE) by $A$. niger and A. terreus in order to increase the degradation rate without any co-substrate or photothermal treatment. Our contribution is to show how to degrade LDPE under minimum nutritional conditions using both LDPE and sucrose as carbon sources. Up to $30 \%$ weight loss was obtained by A. niger and A. terreus which were isolated from an Ecuadorian mangrove. The evidence of cracks and biomass growth on the LDPE surface samples showed the potential of both fungi species to operate under low nutrient concentrations. The outlook of the present work was focused on understanding the fungi survival under minimal conditions.
\end{abstract}

Keywords: Laccase, plastics, polymer, SEM, Czapek

\section{INTRODUCTION}

Approximately 12.7 million of metric tons of plastics contaminate the ocean every year, and this amount is equivalent to around $4.6 \%$ of the total plastic waste generated from 192 coastal countries (Jambeck et al., 2015; Wilcox, Mallos, Leonard, Rodriguez, \& Hardesty, 2016; Worm, Lotze, Jubinville, Wilcox, \& Jambeck, 2017). It is estimated that up to 2.41 million tons of plastic currently flow from the global riverine system into the oceans every year (Lebreton et al., 2017). Mapping the plastic concentrations at oceans, it was revealed that the highest concentrations were found in sub-tropical latitudes, with the highest concentration on the North Atlantic gyre, amounting to 2,324 pieces $/ \mathrm{km}^{2}$ (Cole, Lindeque, Halsband, \& Galloway, 2011). Meanwhile, the plastic production is still increasing up to almost 330 Mt per year worldwide (Amélineau et al., 2016; Worm et al., 2017). The major concern connected with plastics being dumped into oceans is that they fragment into particles that are ingested by small marine invertebrates (Jambeck et al., 2015). As a result, the annual dietary exposure for European shellfish accounts to 11,000 microplastics $(<1 \mathrm{~mm})$ per year (Van Cauwenberghe \& Janssen, 2014). Thus, the impact of plastic pollution through ingestion and entanglement is known to affect at least 243 species of marine fauna, ranging from zooplankton to cetaceans, seabirds and marine reptiles (Worm et al., 2017). Besides, the absorbed toxic substances from plastics like plasticizers, coloring agents and flame retardants are transferred into the tissues and organs through ingestion, thus ending up in the food web (Bellas, Borerro, Martinez-Camara, Besada, \& MartinezGomez, 2016; Eriksen et al., 2014). If global actions are not taken, the mismanaged plastic waste would seriously affect the biodiversity and the human health.

Synthetic polymers like low-and high-density polyethylene (LDPE, HDPE), polyvinyl chloride, polystyrene and polypropylene represent approx. $80 \%$ of the worldwide plastic waste (Pathak \& Navneet, 2017). Specifically, the present work 
focuses on LDPE, because it is a major cause of environmental pollution due to its high tensile strength, lightweight, resistance to water, and resistance to microbial attack (Esmaeili, Pourbabaee, Alikhani, Shabani, \& Esmaeili, 2013; Ndahebwa Muhonja, Magoma, Imbuga, \& Makonde, 2018). The degradation of plastics using microorganisms is being reported as a trend option because of the low energy consumption and further stabilization of the resulting biosolids. For biodegradation of plastic polymers, the most widely used bacterial strains are Klebsiella pneumonia, Pseudomonas fluorescens, Pseudomonas aeruginosa, Pseudomonas putida, Clostridium botulinum, Brevibacillus borstelensis, Ideonella sakaiensis (Ahmed et al., 2018; Awasthi, Srivastava, Singh, Tiwary, \& Mishra, 2017; Hadad, Geresh, \& Sivan, 2005; Kyaw, Champakalakshmi, Sakharkar, Lim, \& Sakharkar, 2012; Restrepo-Florez, Bassi, \& Thompson, 2014; Tribedi \& Sil, 2013a). The fungi which degrade synthetic polymers are $R h i$ zopus arrhizus, Penicillium simplicissimum, Aspergillus flavus, Penicillium funiculosum, Aspergillus niger, Penicillium funiculosum, Fusarium, Pestalotiopsis microspore, Curvularia senegalensis and Fusarium solani (Bonhomme et al., 2003; Das \& Kumar, 2014; Esmaeili et al., 2013; Hikmah, Setyaningsih, \& Pangastuti, 2018; Ibrahim, Maraqa, Hameed, Saadoun, \& Maswadeh, 2011; Jung, Yang, \& Su, 2018; Leja \& Lewandowicz, 2010). The degradation of synthetic polymers is performed by altering the chemical and physical properties of the polymer through enzymatic cleavage, mainly by laccases (Fujisawa, Hirai, \& Nishida, 2001; Pathak \& Navneet, 2017). The partial degradation of polyethylene is achieved after UV irradiation, thermal treatment or oxidation with acid; thus, these pre-treatments reduce the polymeric chain size and therefore the carboxyl, carbonyl, and hydroxyl groups are easily degraded by microorganisms (Sarmah \& Rout, 2018).

The aim of this study was focused on polyethylene degradation, based on the fact that it represents nearly $64 \%$ of all the synthetic plastics produced (Tribedi \& Sil, 2013). The following contributions are presented herein:

- Formulation of a culture media to growth $A s-$ pergillus niger and terreus, which were further used for the degradation of low density polyethylene (LDPE);

- Evaluation of the weight loss of LDPE as a result of the fungal degradation performed by Aspergillus niger and terreus, which were isolated from an Ecuadorian mangrove.

The significance of this research relies on a minimalistic perspective on the design of degradation strategies, in which neither LDPE thermal nor photo-oxidation pre-treatment were used.

\section{METHODS}

\section{Sampling and isolation}

The soil samples were collected at three points on the Santay Island mangrove (Guayaquil, Ecuador) as shown in Figure 1: coastal zone (P1), mid zone (P2) and landward zone (P3). Each sample of soil $(1 \mathrm{Kg})$ consisted of 10 sub-samples, randomly collected from 10 different points over an

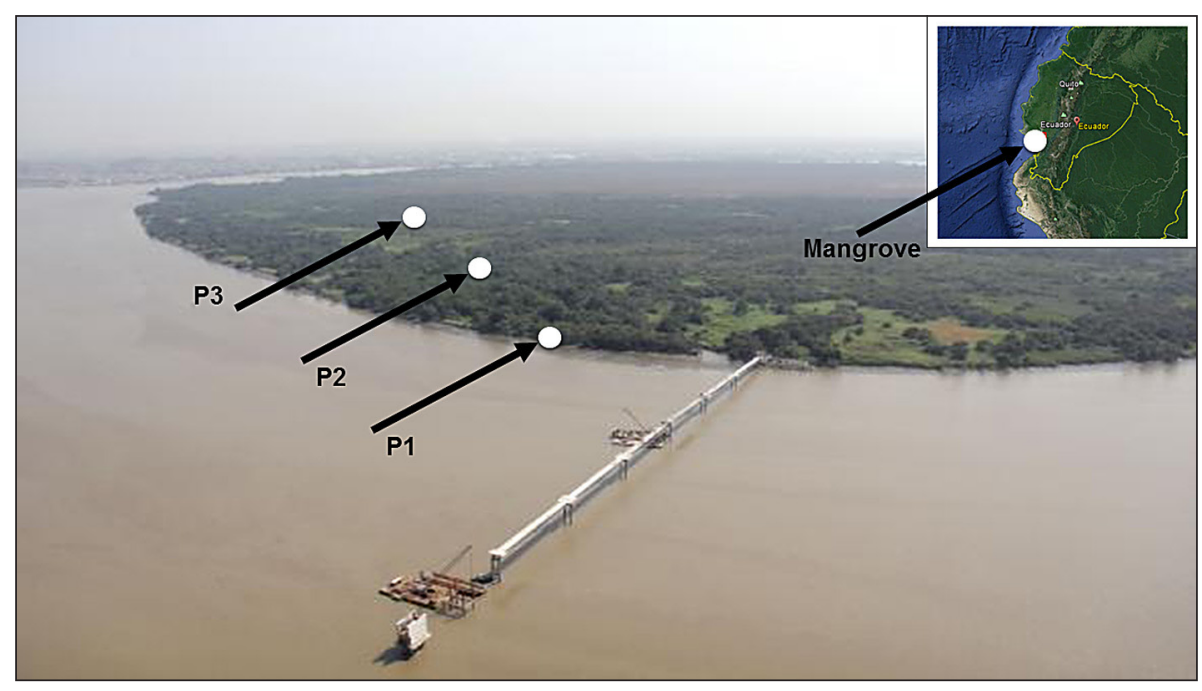

Fig. 1. Sampling points (P1, P2 and P3) where Aspergillus niger and terreus were isolated at the Santay mangrove in Guayaquil, Ecuador 
area of approximately $10 \mathrm{~m}^{2}$ at a depth of approx. $5 \mathrm{~cm}$. After the sampling, a soil extract was prepared by pouring $20 \mathrm{~g}$ of the well-mixed soil sample into a $300 \mathrm{~mL} 1 X$ PBS solution $(8 \mathrm{~g} / \mathrm{L} \mathrm{NaCl}$, $0.6 \mathrm{~g} / \mathrm{L} \mathrm{KH}_{2} \mathrm{PO}_{4}, 1.2 \mathrm{~g} / \mathrm{L} \mathrm{Na}_{2} \mathrm{HPO}_{4}$ and $0.2 \mathrm{~g} / \mathrm{L}$ $\mathrm{KCl}$ ). A $1 \mathrm{~mL}$ of soil extract was poured into Petri dishes over Sabouraud agar (TM Media, India) as culture media, adding $0.5 \mathrm{~mL}$ of chloramphenicol to prevent the bacterial growth. After this inoculation, the Petri dishes were incubated at $37^{\circ} \mathrm{C}$ for 4 days. The organisms found were evaluated according to their morphological characteristics such as conidial heads, mycelial color, shape and roughness, using an optical microscope (Unico M280, USA) (McClenny, 2005). The organisms that were not of interest for the present work were discarded. The fungi colonies which presented morphological characteristics that were similar to the ones reported for Aspergillus spp. were isolated in Sabouraud agar medium for 7 days at $37^{\circ} \mathrm{C}$.

\section{Biodegradation of LDPE}

The LDPE films with a thickness of $100 \mu \mathrm{m}$ were cut into squares of $2 \mathrm{~cm}^{2}$ and weighed using an analytical balance (Kerns, USA). They were placed over a Czapek agar $(15 \mathrm{~g} / \mathrm{L}$ of agaragar, $0.5 / \mathrm{L} \mathrm{g}$ of KCl, $1.0 \mathrm{~g} / \mathrm{L}$ of $\mathrm{K}_{2} \mathrm{HPO}_{4}, 2 \mathrm{~g} / \mathrm{L}$ of $\mathrm{NaNO}_{3}, 30 \mathrm{~g} / \mathrm{L}$ of sucrose, $0.01 \mathrm{~g} / \mathrm{L}$ of $\mathrm{FeSO}_{4}$ and $0.5 \mathrm{~g} / \mathrm{L}$ of $\mathrm{MgSO}_{4}$, and chloramphenicol). For the biodegradation test, $A$. niger and $A$. terreus (10 replicates for each sampling point P1, P2 and
P3) were inoculated over the LDPE samples, as shown in Figure 1. The LDPE weight loss was determined after an incubation time of 77 days at $37^{\circ} \mathrm{C}$. Small samples were washed with ethanol, cut into squares of $0.5 \mathrm{~cm}^{2}$ and then fixed with osmium tetraoxide $\left(\mathrm{OsO}_{4}\right)$ for 24 hours. Then, a dehydration step was carried out by freezing the samples with $100 \%$ t-butanol solution for 6 hours. The samples were later coated with gold for 20 seconds. A scanning electron microscope (JEOLJSM 5310, Japan) was used to observe the LDPE biodegradation (Amano \& Diaz, 2015). The biodegradation process presented herein did not use any thermal or photo-oxidation treatment.

The following Equation (1) was used to compute the percent of loss weight of LDPE over a period of 77 days:

$$
\text { Removal, } \%=\frac{m_{O}-m_{f}}{m_{O}} * 100
$$

where: $m_{o}$ - initial weight of LDPE;

$m_{f}-$ final weight of LDPE after 77 days of biodegradation.

\section{RESULTS AND DISCUSSION}

The isolates of $A$. niger were sampled from three different points at the Santay Island mangrove (P1, P2 and P3). However, Aspergillus terreus was found only in P1. We tested if taking the fungi from different points would have any
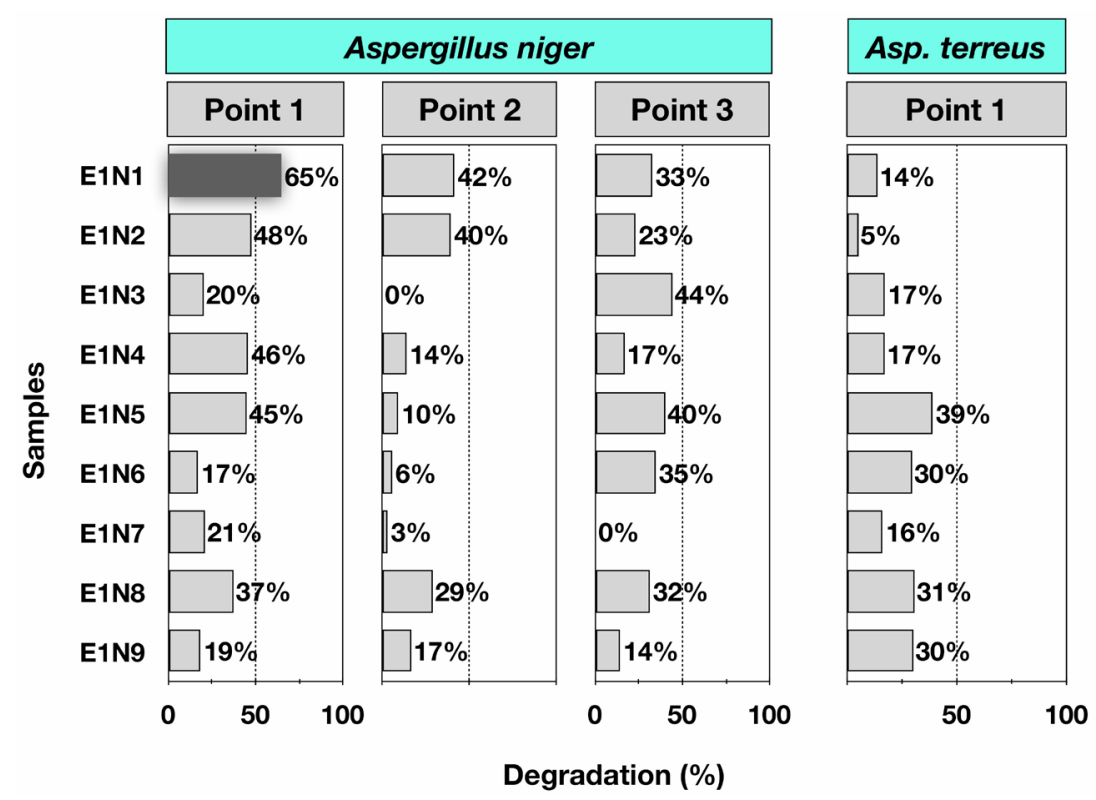

Fig. 2. Dry weight loss of LDPE in percent of $A$. niger and A. terreus which were isolated from three different geographical points (P1, P2 and P3) 
influence on the degradation process. Figure 2 shows the LDPE weight loss percent over a period of 77 days. The results revealed that $A$. niger (from Point 1) could degrade up to approx. 35.3\% of polymer, on average; meanwhile, A. terreus (from Point 1) reduced the weight of the polymer by an average of $22.14 \%$. Both results show a high degradation potential if compared with the ones previously reported in literature (Table 1).

We compared the data only from Point 1 because $A$. terreus only grew in that particular point. According to Figure 3, the weight loss data from A. niger and terreus from Point 1 follows a normal distribution (Fig. 3B). A two-way T-student (Fig. 3A) determined that the loss of LDPE weight from both fungi were statistical different $(p<0.01)$.

Polyethylene is a synthetic polymer which is resistant to biodegradation as carbon source, because of its highly stable $\mathrm{C}-\mathrm{C}$ and $\mathrm{C}-\mathrm{H}$ covalent bonds. As consequence, microbial cells cannot easily penetrate the polymer surface due to the lack of readily oxidizable or/and hydrolyzable chemical groups (Gautam, Bassi, \& Yanful, 2007; Hadad et al., 2005). However, the microbes still managed to do it. According to Figure 4, the microbial degradation of polyethylene starts at the polymer surface. Many authors agree that degradation occurs either by the secretion of extracellular or intracellular enzymes. It is argued that the penetration and distribution ability of Aspergillus hyphae is an example of fungal tip polarized growth, in which neurons, root hairs and pollen tubes are extended over the polymer (Esmaeili et al., 2013; Riquelme, 2013; Sarmah $\&$ Rout, 2018). In this way, the polyethylene integrity is fragmented, causing it to become more brittle and hydrophilic (Hakkarainen \& Albertsson, 2004). As consequence, the diffusion of enzymes increases, and the transformation of polymers into monomers takes place as well. Once the size of the molecules is reduced, the oxidation process is performed, where the remaining molecules are transformed to carboxylic acid which is subsequently metabolized in the Krebs cycle, forming the citric acid as a metabolite (RestrepoFlorez et al., 2014). Figure 4 shows the colonization of Aspergillus niger and Aspergillus terreus over the LDPE films over a period of 77 days.

The aerobic degradation of plastic polymers is performed via hydrolysis by such enzymes as esterases, laccases, and lipases (Ahmed et al.,

A)

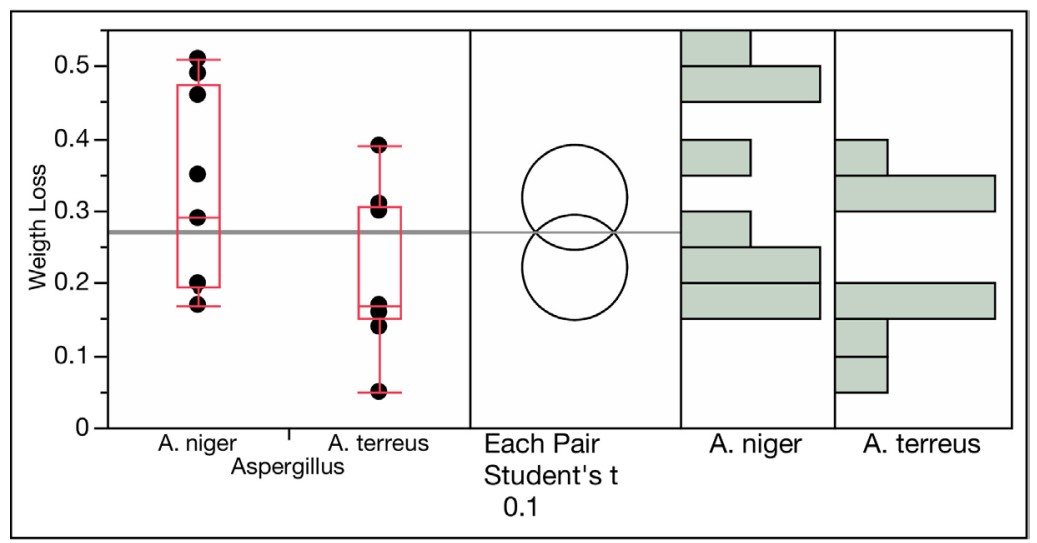

B)

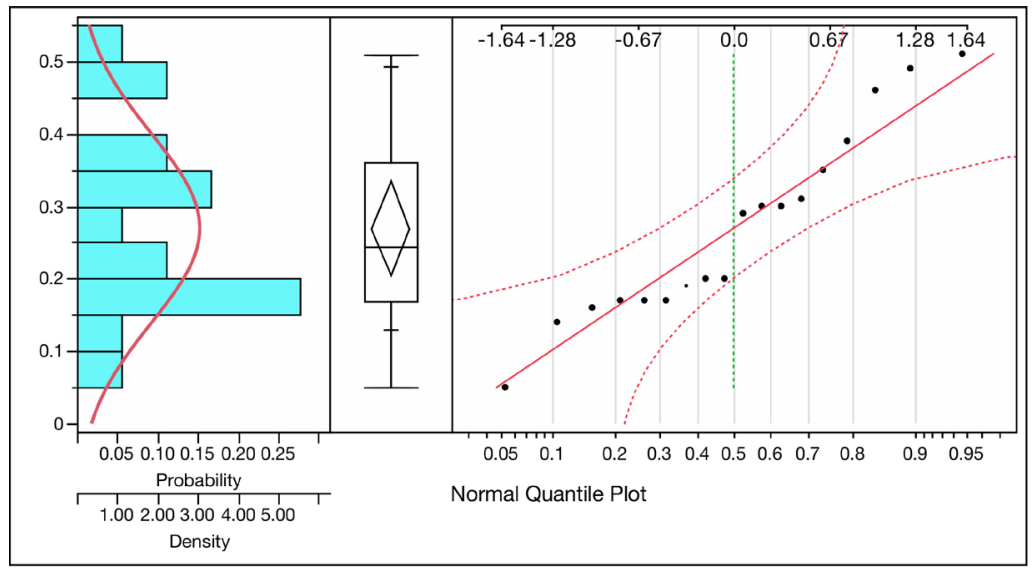

Fig. 3. Statistical analysis of weight loss data. (A) Two-way T-student and (B) normal quantile plot 
A)

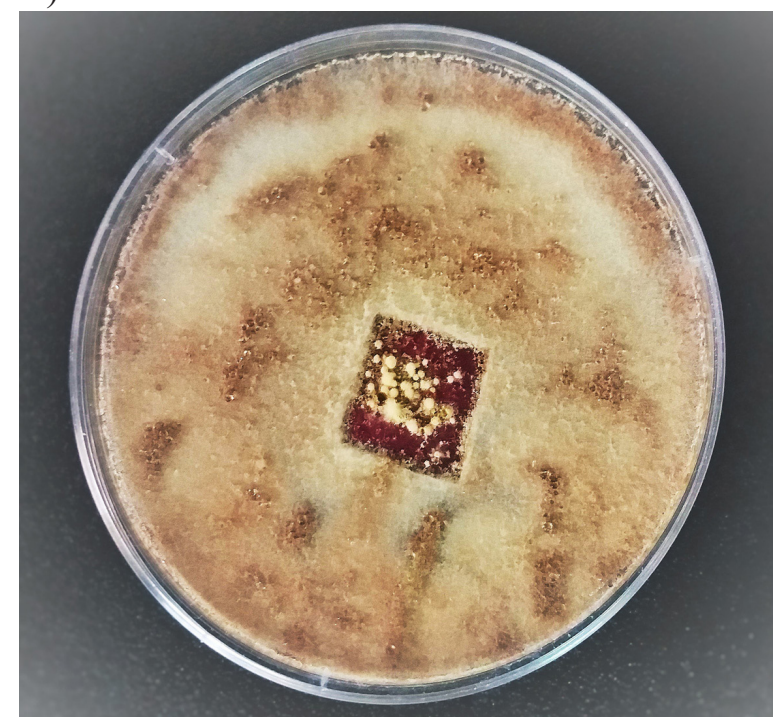

B)

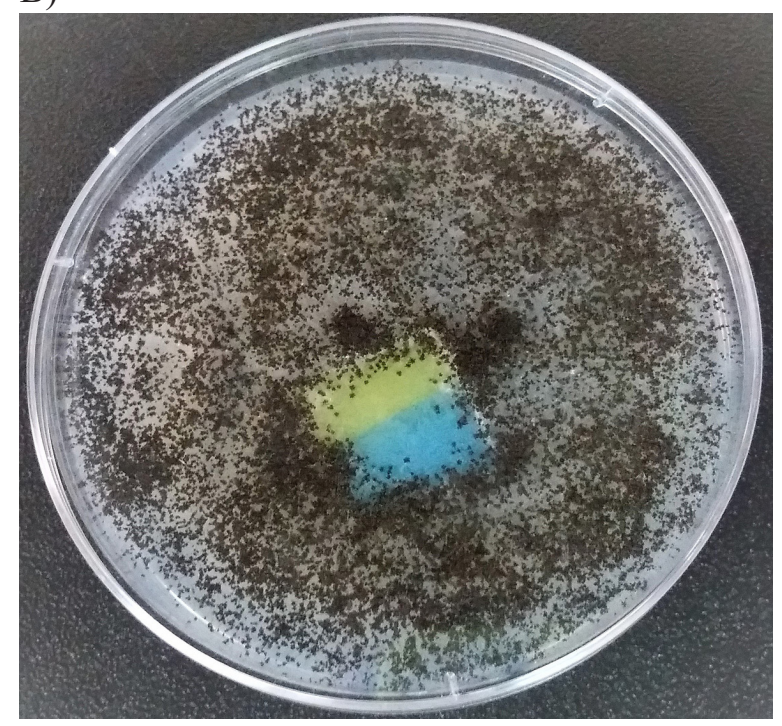

Fig. 4. Fungi growth over LDPE films (A) Aspergillus niger, (B) Aspergillus terreus

2018; Fujisawa et al., 2001; Ndahebwa Muhonja et al., 2018; Tokiwa, Calabia, Ugwu, \& Aiba, 2009). In particular, fungal laccase is a polyphenol oxidoreductase that contains copper atoms in its active center and is involved in the degradation of lignin as well as plastic polymers (Brijwani, Rigdon, \& Vadlani, 2010; de Vries \& Visser, 2001; Tamayo Ramos, Barends, Verhaert, \& de Graaff, 2011). One degradation mechanism of laccase occurs with the reduction of oxygen to water accompanied with one electron oxidation; this oxidation results in the generation of an oxygen-centered free radical compound that can be converted to quinone in a second enzyme catalyzed reaction (Brijwani et al., 2010). Because of this reaction, there is now an increasing application of laccase mediated surface activation, with a view to grafting materials of interest (Iqbal, Kyazze, Tron, \& Keshavarz, 2018). Another degradation mechanism converts carbonyl groups from the polymer to alcohols by monooxygenases; the alcohol is then oxidized to an aldehyde by an alcohol dehydrogenase enzyme; later, an aldehyde dehydrogenase converts aldehydes to fatty acids, which thereafter are degraded inside cells by a $\beta$-oxidation pathway (Gautam et al., 2007). Moreover, A. terreus is a prolific producer of secondary metabolites and its biosynthetic repertoire includes the mycotoxins citrinin, citreovirdin, and patulin, which could be also involved in polymers degradation (Bennett, 2009). Figure 5 shows the growth of $A$. niger and terreus over LDPE films over a period of 77 days, where cracks were clearly formed in the plastic films.
The rate of polyethylene degradation would be boosted if a more oxidized surface were used as a substrate. For example, other authors applied starch as co-substrate. Co-substrates modify the properties such as crystallinity level and morphological changes of the original polymer; as a consequence, the biodegradation of the polymer would be facilitated (Awasthi et al., 2017). Another attempt at increasing the hydrophilicity and then facilitating the colonization of polyethylene on the polymeric surface involves by adding nonionic surfactants to the culture medium (Hadad et al., 2005). The biodegradation of polyethylene is positively affected by pretreatment with ultraviolet light (photo-oxidation), with additives, and with antioxidants, since the chemical structure of polyethylene is similar to that of linear alkanes monomers (Albertsson, Andersson, \& Karlsson, 1987). Both the reduction of molecular weight and the polymers oxidation depend on the interaction effects between the biotic and abiotic factors (thermal treatments or photo-oxidation). Therefore, a photo-thermal or chemical pretreatment increase the surface hydrophilicity of the polymer by the formation of additional groups such as carbonyl groups that can be metabolized by microorganisms (Esmaeili et al., 2013). In the present work, we increased the concentration of sucrose to accelerate the fungi growth and to promote the colonization over the LDPE film. We found out that the Czapek media was an effective alternative to boost the degradation of plastic. In Table 1, we compare the LDPE loss weight of different studies and their pre-treatments, respectively. In 


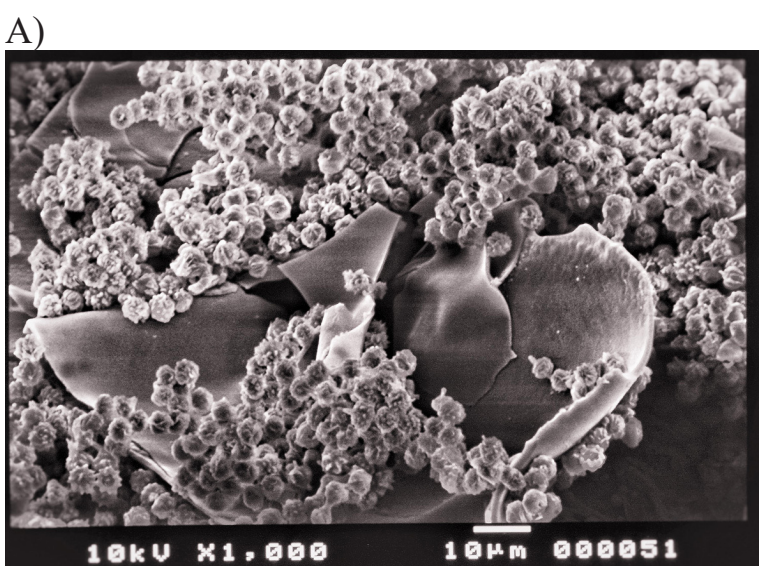

C)

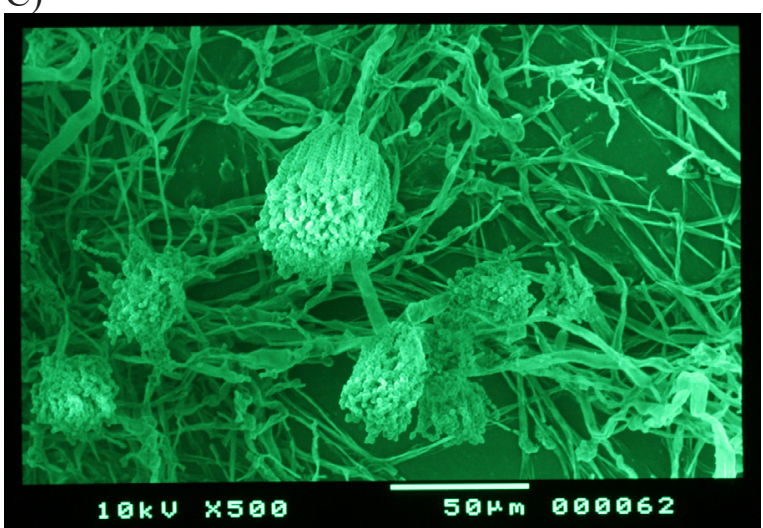

B)

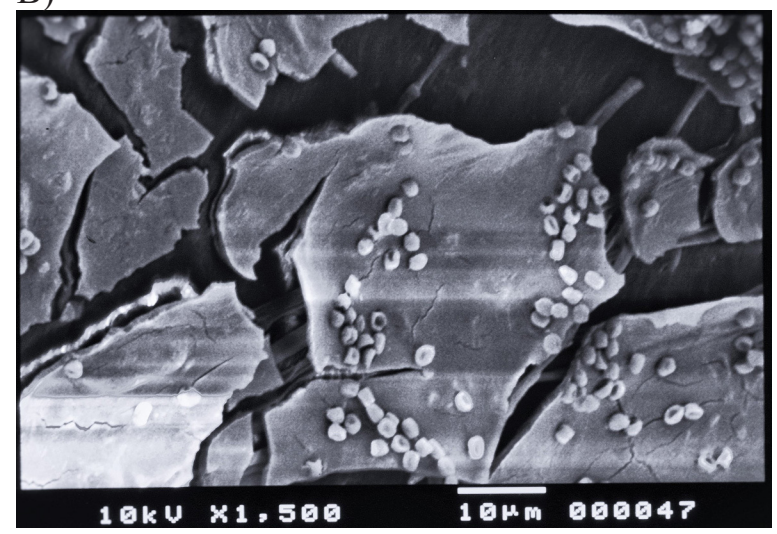

D)

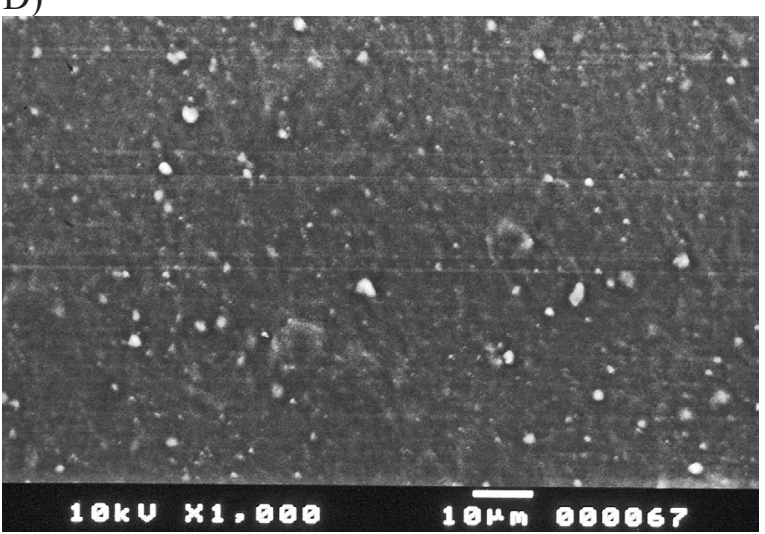

Fig. 5. SEM micrographs of fungi over LDPE films. (A) A. niger hypha over LDPE film. (B) A. niger over LDPE films after 77 days. (C) A. terreus conidia over LDPE. (D) LDPE sample with no fungi

Table 1. LDPE degradation from different microorganisms

\begin{tabular}{|l|c|c|c|c|}
\hline \multicolumn{1}{|c|}{$\begin{array}{c}\text { Culture media to } \\
\text { degrade LDPE }\end{array}$} & Pre-treatment & $\%$ loss weight & Microorganism & Reference \\
\hline $\begin{array}{l}\text { Rose Bengal broth } \\
\text { medium }\end{array}$ & None & $10 \%$ in 28 days & $\begin{array}{c}\text { Bacillus, Micrococcus, } \\
\text { Listeria and Vibrio }\end{array}$ & $\begin{array}{c}\text { (Raaman, Rajitha, } \\
\text { Jayshree, \& Jegadeesh, } \\
2012)\end{array}$ \\
\hline Mangrove soil & None & $5 \%$ in 56 days & $\begin{array}{c}\text { Aspergillus niger, } \\
\text { Aspergillus japonicus }\end{array}$ & $\begin{array}{c}\text { (Kumar, Hatha, \& Christi, } \\
2007)\end{array}$ \\
\hline Forest sandy soil & $\begin{array}{c}\text { Thermal degradation at } \\
55^{\circ} \mathrm{C}\end{array}$ & $60 \%$ in 540 days & & $\begin{array}{c}\text { (Chiellini, Corti, \& Swift, } \\
2003)\end{array}$ \\
\hline Mineral salt medium & None & $9 \%$ in 60 days & Fusarium sp. & (Das \& Kumar, 2014) \\
\hline Farmland soil & 25 days under UV light & $29.5 \%$ in 126 days & $\begin{array}{c}\text { Aspergillus sp., } \\
\text { Lysinibacillus sp. }\end{array}$ & (Esmaeili et al., 2013) \\
\hline Mineral medium & UV photo-oxidization & $11 \%$ in 30 days & Brevibaccillus borstelensis & (Hadad et al., 2005) \\
\hline Mineral salt medium & None & $7.5 \%$ in 35 days & Trichoderma spp. & (Hikmah et al., 2018) \\
\hline $\begin{array}{l}\text { Mineral oil and nonionic } \\
\text { surfactant Tween } 80\end{array}$ & None & $5 \%$ in 45 days & Pseudomonas sp. & (Tribedi \& Sil, 2013b) \\
\hline
\end{tabular}

summary, several synergistic biotic and abiotic factors results in different degradation times.

\section{CONCLUSIONS}

Aspergillus niger and terreus were isolated from a mangrove in Ecuador and they degraded up to $35.3 \%$ and $22.14 \%$ of LDPE films weight over a period of 77 days. In the present study, a rich in sucrose culture media was used, which is believed to enhance the fungal degradation process. It is argued that the microbial degradation of polyethylene starts at the polymer surface by the secretion of extracellular or intracellular enzymes, laccase being one of them. Furthermore, the penetration and distribution ability of Aspergillus hyphae is an 
example of fungal tip polarized growth, which explains the rapid and vast colonization over the LDPE films.

\section{Acknowledgements}

The authors thank SEM specialists Yasuji Amano and Carlos Cepeda from Instituto Nacional de Investigación en Salud Pública (INSPI) for their assistance in microscopy observation.

\section{REFERENCES}

1. Ahmed, T., Shahid, M., Azeem, F., Rasul, I., Shah, A.A., Noman, M., Muhammad, S. (2018). Biodegradation of plastics: current scenario and future prospects for environmental safety. Environmental Science and Pollution Research, 25(8), 72877298. https://doi.org/10.1007/s11356-018-1234-9

2. Albertsson, A.-C., Andersson, S.O., \& Karlsson, S. (1987). The mechanism of biodegradation of polyethylene. Polymer degradation and stability, 18(1), 73-87.

3. Amano, Y., \& Diaz, L. (2015). Introduction to Electronic Microscopy: Principles and Applications (3rd ed.). Instituto Nacional de Investigación en Salud Pública (INSPI).

4. Amélineau, F., Bonnet, D., Heitz, O., Mortreux, V., Harding, A.M.A., Karnovsky, N., ... Grémillet, D. (2016). Microplastic pollution in the Greenland Sea: Background levels and selective contamination of planktivorous diving seabirds. Environmental Pollution, 219, 1131-1139. https://doi. org/10.1016/j.envpol.2016.09.017

5. Awasthi, S., Srivastava, P., Singh, P., Tiwary, D., \& Mishra, P.K. (2017). Biodegradation of thermally treated high-density polyethylene (HDPE) by Klebsiella pneumoniae CH001. 3 Biotech, 7(5). https://doi.org/10.1007/s13205-017-0959-3

6. Bellas, J., Borerro, J., Martinez-Camara, A., Besada, V., \& Martinez-Gomez, C. (2016). Ingestion of microplastics by demersal fish from the Spanish Atlantic and Mediterranean coasts. Marine Pollution Bulletin, 109(1), 55-60. https://doi.org/10.1016/j. marpolbul.2016.06.026

7. Bennett, J.W. (2009). Aspergillus : a primer for the novice. Medical Mycology, 47(s1), S5-S12. https://doi.org/10.1080/13693780802712515

8. Bonhomme, S., Cuer, A., Delort, A.-M., Lemaire, J., Sancelme, M., \& Scott, G. (2003). Environmental biodegradation of polyethylene. Polymer Degradation and Stability, 81(3), 441-452. https://doi. org/10.1016/S0141-3910(03)00129-0

9. Brijwani, K., Rigdon, A., \& Vadlani, P.V. (2010).
Fungal Laccases: Production, Function, and Applications in Food Processing. Enzyme Research, 2010, 1-10. https://doi.org/10.4061/2010/149748

10. Chiellini, E., Corti, A., \& Swift, G. (2003). Biodegradation of thermally-oxidized, fragmented lowdensity polyethylenes. Polymer Degradation and Stability, 81(2), 341-351. https://doi.org/10.1016/ S0141-3910(03)00105-8

11. Cole, M., Lindeque, P., Halsband, C., \& Galloway, T.S. (2011). Microplastics as contaminants in the marine environment: A review. Marine Pollution Bulletin, 62(12), 2588-2597. https://doi. org/10.1016/j.marpolbul.2011.09.025

12. Das, M.P., \& Kumar, S. (2014). Microbial deterioration of low density polyethylene by Aspergillus and Fusarium sp. Int J Chem Tech Res, 6(1), 299-305.

13. de Vries, R.P., \& Visser, J. (2001). Aspergillus Enzymes Involved in Degradation of Plant Cell Wall Polysaccharides. Microbiology and Molecular Biology Reviews, 65(4), 497-522. https://doi. org/10.1128/MMBR.65.4.497-522.2001

14. Eriksen, M., Lebreton, L. C.M., Carson, H.S., Thiel, M., Moore, C.J., Borerro, J.C., ... Reisser, J. (2014). Plastic Pollution in the World's Oceans: More than 5 Trillion Plastic Pieces Weighing over 250,000 Tons Afloat at Sea. PLoS ONE, 9(12), e111913. https:// doi.org/10.1371/journal.pone.0111913

15. Esmaeili, A., Pourbabaee, A.A., Alikhani, H.A., Shabani, F., \& Esmaeili, E. (2013). Biodegradation of Low-Density Polyethylene (LDPE) by Mixed Culture of Lysinibacillus xylanilyticus and Aspergillus niger in Soil. PLoS ONE, 8(9), e71720. https://doi.org/10.1371/journal.pone.0071720

16. Fujisawa, M., Hirai, H., \& Nishida, T. (2001). Degradation of polyethylene and nylon- 66 by the laccase-mediator system. Journal of Polymers and the Environment, 9(3), 103-108.

17. Gautam, R., Bassi, A.S., \& Yanful, E.K. (2007). A review of biodegradation of synthetic plastic and foams. Applied Biochemistry and Biotechnology, 141(1), 85-108.

18. Hadad, D., Geresh, S., \& Sivan, A. (2005). Biodegradation of polyethylene by the thermophilic bacterium Brevibacillus borstelensis. Journal of Applied Microbiology, 98(5), 1093-1100. https:// doi.org/10.1111/j.1365-2672.2005.02553.x

19. Hakkarainen, M., \& Albertsson, A.-C. (2004). Environmental Degradation of Polyethylene. En A.-C. Albertsson (Ed.), Long Term Properties of Polyolefins (Vol. 169, pp. 177-200). https://doi. org/10.1007/b13523

20. Hikmah, M., Setyaningsih, R., \& Pangastuti, A. (2018). The Potential of Lignolytic Trichoderma Isolates in LDPE (Low Density Polyethylene) Plastic Biodegradation. IOP Conference Series: 
Materials Science and Engineering, 333, 012076. https://doi.org/10.1088/1757-899X/333/1/012076

21. Ibrahim, I.N., Maraqa, A., Hameed, K.M., Saadoun, I.M., \& Maswadeh, H.M. (2011). Assessment of potential plastic-degrading fungi in Jordanian habitats. Turkish Journal of Biology, 35(5), 551-557.

22. Iqbal, H.M.N., Kyazze, G., Tron, T., \& Keshavarz, T. (2018). Laccase from Aspergillus niger : A novel tool to graft multifunctional materials of interests and their characterization. Saudi Journal of Biological Sciences, 25(3), 545-550. https://doi. org/10.1016/j.sjbs.2016.01.027

23. Jambeck, J.R., Geyer, R., Wilcox, C., Siegler, T.R., Perryman, M., Andrady, A., ... Law, K.L. (2015). Plastic waste inputs from land into the ocean. Science, 347(6223), 768. https://doi.org/10.1126/science. 1260352

24. Jung, H.-W., Yang, M.-K., \& Su, R.-C. (2018). Purification, characterization, and gene cloning of an Aspergillus fumigatus polyhydroxybutyrate depolymerase used for degradation of polyhydroxybutyrate, polyethylene succinate, and polybutylene succinate. Polymer Degradation and Stability, 154, 186-194. https://doi.org/10.1016/j.polymdegradstab.2018.06.002

25. Kumar, S., Hatha, A.A.M., \& Christi, K.S. (2007). Diversity and effectiveness of tropical mangrove soil microflora on the degradation of polythene carry bags. Revista de biología Tropical, 55(3-4), 777-786.

26. Kyaw, B.M., Champakalakshmi, R., Sakharkar, M.K., Lim, C.S., \& Sakharkar, K.R. (2012). Biodegradation of Low Density Polythene (LDPE) by Pseudomonas Species. Indian Journal of Microbiology, 52(3), 411-419. https://doi.org/10.1007/ s12088-012-0250-6

27. Lebreton, L.C.M., van der Zwet, J., Damsteeg, J.-W., Slat, B., Andrady, A., \& Reisser, J. (2017). River plastic emissions to the worlds oceans. Nature Communications, 8, 15611. https://doi. org/10.1038/ncomms 15611

28. Leja, K., \& Lewandowicz, G. (2010). Polymer Biodegradation and Biodegradable Polymers-a Review. Polish Journal of Environmental Studies, 19(2).

29. Ndahebwa Muhonja, C., Magoma, G., Imbuga, M., \& Makonde, H.M. (2018). Molecular Characterization of Low-Density Polyethene (LDPE) Degrading Bacteria and Fungi from Dandora Dumpsite, Nairobi, Kenya. International Journal of Microbiology, 2018, 1-10. https://doi. org/10.1155/2018/4167845

30. Pathak, V.M., \& Navneet. (2017). Review on the current status of polymer degradation: a microbial approach. Bioresources and Bioprocessing, 4(1). https://doi.org/10.1186/s40643-017-0145-9

31. Raaman, N., Rajitha, N., Jayshree, A., \& Jegadeesh, R. (2012). Biodegradation of plastic by Aspergillus spp. isolated from polythene polluted sites around Chennai. 1, 4.

32. Restrepo-Florez, J.-M., Bassi, A., \& Thompson, M. R. (2014). Microbial degradation and deterioration of polyethylene: A review. International Biodeterioration \& Biodegradation, 88, 83-90. https://doi. org/10.1016/j.ibiod.2013.12.014

33. Riquelme, M. (2013). Tip Growth in Filamentous Fungi: A Road Trip to the Apex. Annual Review of Microbiology, 67(1), 587-609. https://doi. org/10.1146/annurev-micro-092412-155652

34. Sarmah, P., \& Rout, J. (2018). Efficient biodegradation of low-density polyethylene by cyanobacteria isolated from submerged polyethylene surface in domestic sewage water. Environmental Science and Pollution Research, 25(33), 33508-33520. https://doi.org/10.1007/s11356-018-3079-7

35. Tamayo Ramos, J.A., Barends, S., Verhaert, R. M., \& de Graaff, L.H. (2011). The Aspergillus niger multicopper oxidase family: analysis and overexpression of laccase-like encoding genes. Microbial Cell Factories, 10(1), 78. https://doi. org/10.1186/1475-2859-10-78

36. Tokiwa, Y., Calabia, B.P., Ugwu, C.U., \& Aiba, S. (2009). Biodegradability of Plastics. International Journal of Molecular Sciences, 10(9), 3722-3742. https://doi.org/10.3390/ijms10093722

37. Tribedi, P., \& Sil, A.K. (2013a). Low-density polyethylene degradation by Pseudomonas sp. AKS2 biofilm. Environmental Science and Pollution Research, 20(6), 4146-4153. https://doi.org/10.1007/ s11356-012-1378-y

38. Tribedi, P., \& Sil, A.K. (2013b). Low-density polyethylene degradation by Pseudomonas sp. AKS2 biofilm. Environ Sci Pollut Res, 8.

39. Van Cauwenberghe, L., \& Janssen, C. R. (2014). Microplastics in bivalves cultured for human consumption. Environmental Pollution, 193, 65-70. https://doi.org/10.1016/j.envpol.2014.06.010

40. Wilcox, C., Mallos, N.J., Leonard, G.H., Rodriguez, A., \& Hardesty, B.D. (2016). Using expert elicitation to estimate the impacts of plastic pollution on marine wildlife. Marine Policy, 65, 107114. https://doi.org/10.1016/j.marpol.2015.10.014

41. Worm, B., Lotze, H.K., Jubinville, I., Wilcox, C., \& Jambeck, J. (2017). Plastic as a Persistent Marine Pollutant. Annual Review of Environment and Resources, 42(1), 1-26. https://doi.org/10.1146/ annurev-environ-102016-060700. 